http://jmscr.igmpublication.org/home/ ISSN (e)-2347-176x ISSN (p) 2455-0450

crossref DOI: https://dx.doi.org/10.18535/jmscr/v8i1.117

\title{
Early Extubation is Enhanced in Patients Receiving Local Infiltration over the Opioid Based Anaesthesia in Cardiac Surgery Patients
}

\author{
Authors \\ Hakeem Zubair Ashraf ${ }^{1^{*}}$, Mohd Yaqoob Khan², Nadeem-ul-Nazeer Kawoosa ${ }^{3}$, \\ Haroon Naqshi ${ }^{4}$, Abdul Majeed Dar ${ }^{5}$, Mohammad Akbar Bhat ${ }^{6}$, Talib Khan ${ }^{7}$ \\ ${ }_{1,2,3,4,5,6}$ CVTS , SKIMS, Soura, Srinagar, INDIA \\ ${ }^{7}$ Cardiac anaesthesia, SKIMS, Soura, Srinagar INDIA \\ *Corresponding Author \\ Hakeem Zubair Ashraf
}

\begin{abstract}
Objective: To study the comparative effect of local anaesthetic infiltration and systemic opioid analgesia on the early extubation in cardiac surgeries.

Introduction: Sternotomy inflicts severe surgical trauma and affects the pulmonary functions and the subsequent recovery. Various modalities have been employed to alleviate the implications of pain. Local infiltration of anaesthetics has been documented with good results.

Material and Methods: Eighty (80) patients in the age group of 18 to 50 years planned for open heart surgeries were divided into two groups $A$ and $B$ of forty (40) patients each. Group A patients received infusion of fentanyl @ $1 \mathrm{mcg} / \mathrm{kg} / \mathrm{hr}$ while as in group B $20 \mathrm{ml}$ of $0.5 \%$ Ropivacaine was given subcutaneously at sternotomy site. In addition, in group A, $50 \mathrm{mcg}$ bolus of fentanyl was given at the time of sternotomy while as group B patients received $10 \mathrm{ml}$ bolus of $0.2 \%$ Ropivacaine.

After completion of surgery patients were shifted to Cardiac ICCU and were observed for early awakening and extubation.

Results: $85 \%$ of group B patients were extubated within 2 hours after surgery. The mean time duration of post operative ventilation in group B patients was 1.7 hours. In contrast $32.5 \%$ of patients of the Group A could be extubated within 2 hours. The mean duration of postoperative ventillation in group B was 5.2 hours. Furthermore the group B patients had a better post operative pain control and breathing pattern than the group A patients.

None of the patients of the either group was re-intubated.

Conclusion: Infiltration of surgical wounds with local anaesthetics improves pain scores and reduces opioid consumption and facilitates early extubation and improvement of post extubation breathing and blood gas parameters.

Keywords: Cardiac Surgery, Local infiltration, systemic opioid anaesthesia, effects, recovery. anaesthesia has greatly evolved over the last decade;

\section{Introduction}

Cardiac surgery induces considerable pain and impairment in pulmonary functions and increases morbidity and mortality. Standardisation of cardiac therefore, evaluation of the evidence is needed to assess the comparative benefits of different techniques of pain management, to guide clinical practice and to identify areas of further research. ${ }^{[1]}$
\end{abstract}


Sternotomy inflicts severe surgical trauma and affects the pulmonary functions and the subsequent recovery. Various modalities have been employed to alleviate the implications of pain. Local infiltration of anaesthetics has been documented with good results. ${ }^{[2]}$

Patients' pain relief by parasternal single injection of Bupivacaine in early postoperative period can facilitate earlier ventilator weaning and tracheal extubation after open heart surgery as well as achieving lower pain scores and narcotic requirements. ${ }^{[3]}$ The use of large doses of opioid analgesics to treat pain after cardiac surgery can prolong the time to tracheal extubation and interfere with recovery of bowel and bladder function in the postoperative period. ${ }^{[4]}$ Wound infusion and patientcontrolled analgesia are superior to patientcontrolled analgesia alone in reducing pain at 1, 3, and 90 days after cardiac surgeries. ${ }^{[5]}$

We studied the comparative efficacy and applied practical benefits of local anaesthetic infiltration and systemic opioid administration in cardiac surgery patients and tried to find out the related outcomes.

\section{Material and Methods}

A total of eighty (80) patients were divided into two groups A and B of forty(40) patients each. Patients discussed and planned for open heart surgeries in the age group of 18 to 50 years of ASA 1-4 were included. Following patients were excluded;

Refusal to surgery

Allergic episodes to local anaesthetics or opioid

Opioid addiction and low mental capability

Previous cardiothoracic surgery

Respiratory diseases

All study patients were administered pre-anesthetic medication with Ranitidine and Domperidone and were kept NPO for 8 hours prior to surgery. Antibiotic was given half an hour before shifting to OR. After establishing IV access, induction was done by Midazolam ( $5 \mathrm{mg}$ ), Vecuronium (1 mg/kg) and Fentanyl (200 mcg).

In one group (group A) infusion of fentanyl was given@ $1 \mathrm{mcg} / \mathrm{kg} / \mathrm{hr}$ while as in group B $20 \mathrm{ml}$ of $0.5 \%$ Ropivacaine was given subcutaneously on sternotomy site. In addition, in group A, $50 \mathrm{mcg}$ bolus of fentanyl was given at the time of sternotomy while as group B patients received 10 $\mathrm{ml}$ bolus of $0.2 \%$ Ropivacaine.

After completion of surgery patients were shifted to Cardiac ICCU and were observed for early awakening and extubation.

\section{Results}

34 out of $40(85 \%)$ group B patients were extubated within 2 hours in cardiac ICCU after surgery. 3 $(7.5 \%)$ patients were extubated within 5 hours and remaining 1 patient needed overnight intubation and gradual weaning from mechanical ventillation. The mean time duration of post operative ventilation in group B patients was 1.7 hours. Compared to this, only 13 out of $40(32.5 \%)$ patients of the Group A could be extubated within 2 hours while as the remaining $27(67.5 \%)$ patients were extubated after 5 hours. The mean duration of postoperative ventillation in group B was 5.2 hours.

Furthermore the group B patients had a better post operative pain control and breathing pattern than the group A patients.

None of the patients of the either group was reintubated.

\section{Discussion}

A parasternal intercostal block is a safe, simple, and effective adjunct for optimizing of pain control and reducing opioid analgesics after adult cardiac surgery. This practice helps clinicians with an effective treatment for sternal wound pain. ${ }^{[6]}$

Early tracheal extubation after cardiac surgery has become more popular and it can be safe and result in decreased cost and improved outcome. ${ }^{[7]}$

Median sternotomy incision and the mediastinal tube insertion site are main sources of pain in cardiac surgical patients ${ }^{[8]}$

Therefore, infiltration of local anesthetic agents near the sternotomy wound is a possible way of diminishing early postoperative pain. This method may reduce opioid requirements, and subsequent opioid induced side effects such as sedation and respiratory depression. ${ }^{[9]}$ One of the most important 
parameters in rapid weaning of cardiac surgery patients from ventilator is control and reduction of pain in early postoperative period. Reduction of pain can lead to reduction of intubation time and narcotic requirements and improvement of $\mathrm{ABG}$ parameters in early postoperative period. ${ }^{[8,9]}$

\section{Conclusions}

Infiltration of the surgical wounds with local anaesthetics has been shown to improve pain scores or reduce opioid consumption after various types of major cardiac surgery. This has facilitated the early extubation and post-extubation improvement in breathing and blood gas parameters.

\section{Acknowledgement}

We are thankful to all the patients who were included in the study to give their informed consent for the procedures carried on them.

\section{References}

1. B. Nachiyunde, L. Lam, "The efficacy of different modes of analgesia in postoperative pain management and early mobilization in postoperative cardiac surgical patients,"A systemic review. School of Nursing and Healthcare Professions, Federation University of Australia.

2. S.U. Rehman, T.A. Siddiqi, A .Hussain, R. Yaseen, R. Tanveer "Efficacy of parasternal injection of Bupivacaine on post operative pain for early extubation in patients undergoing coronary artery by-pass surgery",. J Cardiol Curr Res, 6(4), pp.00210.2016.

3. M. Saeidi, O.A. Davoudi, M.Mir, M. Sadeghi, and M. Mansouri."The efficacy of preventive parasternal single injection of bupivacaine on intubation time, blood gas parameters, narcotic requirement, and pain relief after open heart surgery: A randomized clinical trial study,"J Res Med Sci. 2011 Apr; 16(4): 477-483.

4. P.F. White, S. Rawal, P. Latham, S. Markowitz, T Issioui,L. Chi, S Dellaria , C Shi, Morse "Use of a continuous local anesthetic infusion for pain management after median sternotomy",. Anesthesiology. 2003 Oct, 99(4), pp.918-23.

5. K.M. Chiu, C.C. Wu, M.J. Wang, C.W. Lu, J.S. Shieh, T.Y. Lin, “ Local infusion of Bupivacaine combined with intravenous patient-controlled analgesia provides better pain relief than intravenous patient-controlled analgesia alone in patients undergoing minimally invasive cardiac surgery,". J Thorac Cardiovasc Surg. 2008 Jun,135(6),pp.1348-52. doi: 10.1016j.jtcvs.2008.01.020.

6. A.M. Barr, E Tutungi, A.A. Almeida, "Parasternal intercostal block with ropivacaine for pain management after cardiac surgery: a double-blind, randomized, controlled trial," .J Cardiothoracic Vasc Anesth. 2007 Aug, 21(4),p p.547-53. Epub 2006 Dec 22.

7. T.W. Lee, E. Jacobsohn, “ Pro tracheal extubation should occur routinely in the operating room after cardiac surgery,'J Cardiothorac Vasc Anesth. 2000 Oct, 14(5),pp.603-10

8. M. Singh, R. Gopinath, " Topical analgesia for chest tube removal in cardiac patients"J Cardiothorac Vasc Anesth. 2005 Dec, 19(6), pp.719-22.

9. S.B. McDonald, E. Jacobsohn, D.J.Kopacz, S. Desphande, J.D. Helman, F. Salinas, R.A Hall, "Parasternal block and local anesthetic infiltration with levobupivacaine after cardiac surgery with desflurane: the effect on postoperative pain, pulmonary function, and tracheal extubation times," Anesth Analg. 2005 Jan, 100(1),pp.25-32.

10. Kocabas, S. Yedicocuklu, D. Yuksel, E Uysallar, E. Askar, "Infiltration of the sternotomy wound and the mediastinal tube sites with $0.25 \%$ levobupivacaine as adjunctive treatment for postoperative pain after cardiac surgery," European Journal of Anaesthesiology: October 2008 - Volume 25 - Issue 10 - p 842849. 